\title{
The Effect of Gemcitabine on Cell Cycle Arrest and microRNA Signatures in Pancreatic Cancer Cells
}

\author{
DAISUKE NAMIMA ${ }^{1}$, SHINTARO FUJIHARA ${ }^{1}$, HISAKAZU IWAMA ${ }^{2}$, KOJI FUJITA $^{1}$, \\ TAKANORI MATSUI ${ }^{1}$, MAI NAKAHARA ${ }^{1}$, MEGUMI OKAMURA ${ }^{1}$, MASAHIRO HIRATA $^{1}$, \\ TOSHIAKI KONO ${ }^{1}$, NAOKI FUJTA ${ }^{1}$, HIROKI YAMANA ${ }^{1}$, KIYOHITO KATO ${ }^{1}$, HIDEKI KAMADA ${ }^{1}$, \\ ASAHIRO MORISHITA ${ }^{1}$, HIDEKI KOBARA ${ }^{1}$, KUNIHIKO TSUTSUI $^{2}$ and TSUTOMU MASAKI $^{1}$ \\ ${ }^{1}$ Department of Gastroenterology and Neurology, and \\ ${ }^{2}$ Life Science Research Center, Kagawa University, Kagawa, Japan
}

\begin{abstract}
Background/Aim: Gemcitabine, an inhibitor of DNA synthesis, is the gold standard chemotherapeutic agent for pancreatic ductal adenocarcinoma (PDAC). MicroRNAs (miRNAs) play critical roles in cancers, including PDAC. However, less is known about the effect of gemcitabine on PDAC cells and miRNA expression in PDAC. We evaluated the effect of gemcitabine on the cell cycle of PDAC cells in vitro and in vivo and on the miRNA expression profile. Materials and Methods: Effects of gemcitabine on PK-1 and $P K-9$ cell growth were evaluated using a cell counting kit-8 assay. Xenografted mouse models were used to assess gemcitabine effects in vivo. Results: Gemcitabine inhibited the proliferation and tumour growth of PK-1 cells, and induced $S$ phase cell cycle arrest. Numerous miRNAs were altered upon gemcitabine treatment of PK-1 cells and xenograft models. Conclusion: Altered miRNAs may serve as potential therapeutic targets for improving the efficacy of gemcitabine in PDAC.
\end{abstract}

Pancreatic ductal adenocarcinoma (PDAC) is the seventh leading cause of cancer-related death in both men and women according to the 2017 Global Burden of Disease study (1). Most exocrine pancreatic cancers are adenocarcinomas arising from the ductal epithelium. Surgical resection is the only potential curative treatment for PDAC;

This article is freely accessible online.

Correspondence to: Tsutomu Masaki, MD, Ph.D., Department of Gastroenterology and Neurology, Kagawa University Faculty of Medicine, Graduate School of Medicine, 1750-1 Ikenobe, Miki-cho, Kita-gun, Kagawa 761-0793, Japan. Tel: +81 878912156, Fax: +81 878912158,e-mail: tmasaki@med.kagawa-u.ac.jp

Key Words: Pancreatic neoplasm, gemcitabine, cell cycle, cyclin, microRNA. however, only $15 \%$ to $20 \%$ of patients have resectable disease at initial diagnosis $(2,3)$. The majority of patients have locally advanced or metastatic cancer, and chemotherapy is mainly performed for unresectable PDAC. Gemcitabine monotherapy, a more intensive first-line chemotherapy regimen, has been approved for first-line treatment of patients with metastatic PDAC (4). Gemcitabine is a cell cycle-specific inhibitor of DNA synthesis and ribonucleotide reductase that has become the gold standard chemotherapeutic agent for pancreatic cancer $(5,6)$. However, the response rate to single administration of gemcitabine is not high, and thus, improvement of the therapeutic effect is required. Furthermore, no reliable molecular targets have been identified that can predict or influence the success of gemcitabine in PDAC.

MicroRNAs (miRNAs) are endogenous, single-stranded noncoding RNAs ( $\sim 22$ nucleotides in length) that control gene expression at the post-transcriptional level (7). miRNAs have been shown to function in cell proliferation, differentiation, cell cycle control, and chemotherapy resistance in cancer $(8,9)$. Aberrant expression of miRNAs has been observed in tissue and serum samples from PDAC patients as well as PDAC cell lines, indicating that miRNAs may participate in the pathogenesis of PDAC (1012). We have previously reported on miRNA signatures for chemosensitivity and chemoresistance in hepatocellular and cholangiocellular carcinomas (13-14). We hypothesized, that currently unidentified miRNAs may influence gemcitabine treatment of PDAC and present targets for novel diagnostic and therapeutic options. Better understanding of the effects of gemcitabine on PDAC cells and potentially related miRNAs may provide insights for improving treatment efficacy.

In this experimental study, we analysed the effect of gemcitabine on PDAC cells and examined miRNA signatures of gemcitabine-treated PDAC in in vitro and in vivo models. 


\section{Materials and Methods}

Drugs. Gemcitabine was purchased from Eli Lily Japan (Hyogo, Japan). Gemcitabine was prepared as a $10 \mathrm{mM}$ stock solution in dimethyl sulfoxide (DMSO) and stored at $-20^{\circ} \mathrm{C}$.

Cell lines and culture. The human pancreatic cancer cell lines PK1 and PK-9 were provided by the Japanese Cancer Research Resources Bank (JCRB, Tokyo, Japan). The cell lines were maintained at $37^{\circ} \mathrm{C}$ with $5 \% \mathrm{CO}_{2}$ in RPMI-1640 (Gibco, Grand Island, NY, USA) supplemented with $10 \%$ foetal bovine serum (Wako Pure Chemical Industries, Osaka, Japan), $20 \mathrm{U} / \mathrm{ml}$ penicillin, and $100 \mu \mathrm{g} / \mathrm{ml}$ streptomycin (Invitrogen, Carlsbad, CA, USA).

Cell proliferation assay. The cell proliferation assay was performed as described previously (13). PK-1 and PK-9 cells were seeded into 96-well plates $\left(5.0 \times 10^{3}\right.$ cells $)$ and treated as indicated for $48 \mathrm{~h}$. Cell proliferation was assayed using the CCK- 8 cell counting kit (Dojindo Laboratories, Kumamoto, Japan) according to the manufacturer's instructions. The absorbance was measured at 450 $\mathrm{nm}$ using a microplate reader (Multiskan FC, Thermo Scientific Corp., Waltham, MA, USA).

Cell cycle analyses. PK-1 cells were collected, seeded into 100-mm culture dishes at $1.0 \times 10^{6}$ per dish, and cultured for $24 \mathrm{~h}$. Cells were then treated with $30 \mathrm{nM}$ gemcitabine for 24-48 h. Cell cycle was determined by flow cytometry using the Cytomics FC 500 flow cytometer (Beckman Coulter, Indianapolis, IN, USA), according to the manufacturer's protocol. Data were analysed using Kaluza software (Beckman Coulter). All experiments were performed in triplicate.

Western blotting. Gel electrophoresis and western blotting were performed in accordance with our previously described methods (13). Briefly, proteins were subjected to sodium dodecyl sulphate polyacrylamide gel electrophoresis and then transferred to nitrocellulose membranes. After blocking in 5\% dry skim milk in $0.05 \%$ Tween-20/TBS buffer [25 mM Tris, $0.15 \mathrm{M} \mathrm{NaCl}, 0.05 \%$ (v/v) Tween-20, $\mathrm{pH} 7.5]$, the membranes were incubated with primary antibodies, followed by incubation with peroxidaseconjugated secondary antibodies in 5\% dry skim milk in $0.05 \%$ Tween-20/TBS buffer. The proteins were visualized on an X-ray film using an enhanced chemiluminescence detection system (PerkinElmer Co., Waltham, MA, USA). Band intensities were quantified using ImageJ software 1.52q (NIH, Bethesda, MD, USA) and normalized to $\beta$-actin.

The following primary antibodies were used in this study: $\beta$-actin (1:10,000; Sigma-Aldrich, St. Louis, MO, USA), cyclin D1 $(1: 1,000$; Thermo Fisher Scientific, Waltham, MA, USA), Cdk4 (1:1,000; Santa Cruz Biotechnology, Santa Cruz, CA, USA), Cdk6 (1:1,000, Santa Cruz Biotechnology), and Cdk2 (1:2,000; Santa Cruz Biotechnology). The secondary antibodies included horseradish peroxidase (HRP)-linked anti-mouse and anti-rabbit IgG (1:2,000; Cell Signaling Technology, Boston, MA, USA).

MiRNA array and data analysis. MiRNA array analysis was performed as described in our previous studies (13-14). Briefly, total RNA was isolated from PK-1 cells and tumour tissues using a miRNeasy Mini Kit (Qiagen, Hilden, Germany) according to the manufacturer's instructions. miRNA expression analysis was performed using the miRCURYHy3/Hy5 Power Labeling Kit and human miRNA Oligo chip (v. 21.0; Toray Industries, Tokyo, Japan). The arrays were scanned in a 3D-Gene Scanner 3000 (Toray Industries), and fluorescence images were analysed using the 3DGene extraction version 1.2 software (Toray Industries).

Xenografted tumour model. All animals were treated in accordance with the guidelines of the Kagawa University Committee on Experimental Animals. The Kagawa University Animal Care Committee approved our animal protocols including animal ethics. Sixweek-old BALB/c-nu/nu mice $(\mathrm{n}=18)$ were obtained from Japan SLC (Shizuoka, Japan) and housed and maintained in specific pathogen-free conditions at $20-26^{\circ} \mathrm{C}$. A standard sterilized laboratory diet and water were available ad libitum. A total of $1 \times 10^{6} \mathrm{PK}-1$ cells were injected subcutaneously into the left flank of nude mice. After approximately 2 weeks, when tumours reached a maximal diameter of $>3 \mathrm{~mm}, 18$ mice were randomly assigned into three groups. Mice were administrated PBS only (control) $(\mathrm{n}=6), 40 \mathrm{mg} / \mathrm{kg}$ gemcitabine $(\mathrm{n}=6)$, or $80 \mathrm{mg} / \mathrm{kg}$ gemcitabine $(n=6)$ five times per week intraperitoneally (i.p.). The body weight and tumour volume were monitored every 3 days. Tumour volumes were calculated using the formula $V=$ length $\times$ width $^{2} / 2(15)$. The animals were sacrificed on day 42 after treatments.

Immunohistochemistry. We prepared 5 - $\mu$ m-thick sections from formalin-fixed, paraffin-embedded tissue blocks. To retrieve antigens, the sections were boiled in $10 \mathrm{mmol} / \mathrm{l}$ citrate buffer $(\mathrm{pH}$ 6.0) using a microwave oven (MR-M201 Microwave Processor; Hitachi, Tokyo, Japan) at $500 \mathrm{~W}$ for $5 \mathrm{~min}$. The sections were then dewaxed in xylene, rehydrated in graded alcohol solutions, and then mixed with a solution containing $0.5 \%$ hydrogen peroxidase to block endogenous peroxidase activity. After washing with phosphate-buffered saline, the sections were immunostained. Expression of cyclin D1 was detected by incubation with a mouse $\mathrm{mAb}$ (1:200 dilution) and rabbit pAb (1:50 dilution) overnight. The sections were then incubated for $30 \mathrm{~min}$ with appropriate peroxidase-conjugated secondary antibodies (PK-6102, PK-6101, Vectastain Elite ABC kit, Vector Laboratories, CA, USA).

The standard avidin-biotin-peroxidase complex method (Funakosi Chemical Co., Tokyo, Japan) with diaminobenzidine (Sigma Chemical Co., Tokyo, Japan) as the substrate was employed for detection. Sections were counterstained by Meyer's hematoxylin. Samples treated with phosphate buffer served as the negative controls. Sections were examined microscopically, and nuclei with a brown colour (regardless of staining intensity) were regarded as positive. Cyclin D1-positivity was calculated for both at $40 \times$ magnification by dividing the number of positive cells by the total number of cells counted in five random fields and expressed as a percentage. Images were obtained with a digital image capture system (Olympus, Tokyo, Japan).

Statistical analysis. Data are expressed as the mean \pm standard deviation (SD). All statistical analyses were performed using GraphPad Prism 6 software (GraphPad Software, La Jolla, CA, USA). Nonparametric Wilcoxon/Mann-Whitney $U$-test was used to examine statistical significance between the two groups. A $p$-value less than 0.05 was considered significant.

\section{Results}

Gemcitabine treatment suppresses human PDAC cell growth in vitro. Two human PDAC cell lines, PK-1 and PK-9, were 
PK-1

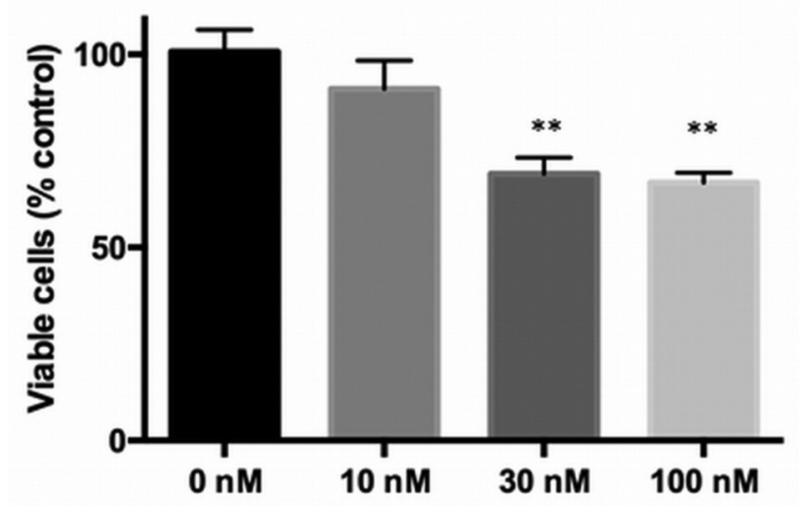

PK-1

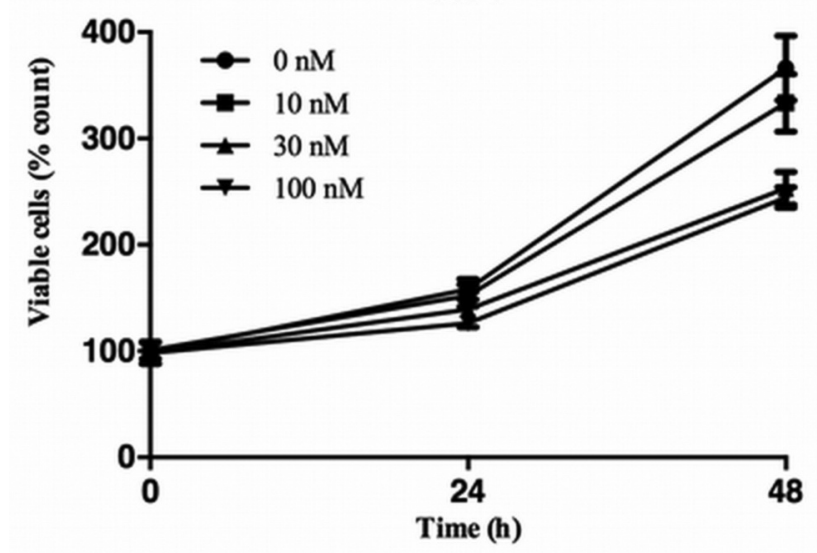

PK-9

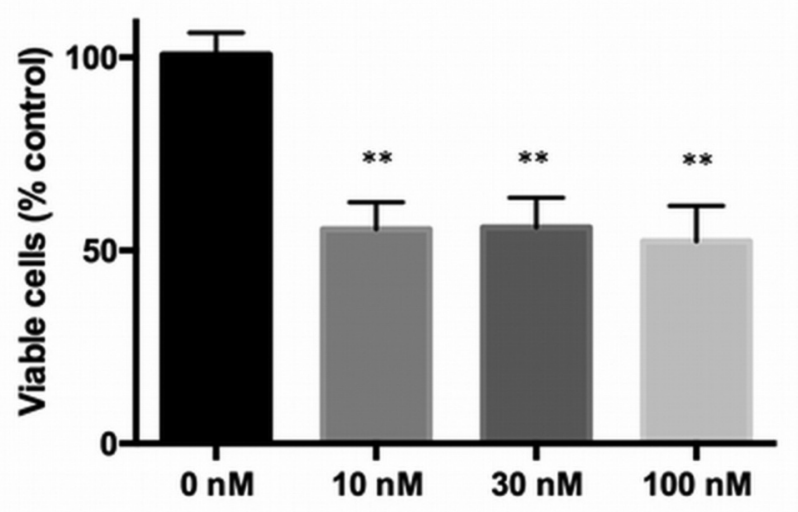

PK-9

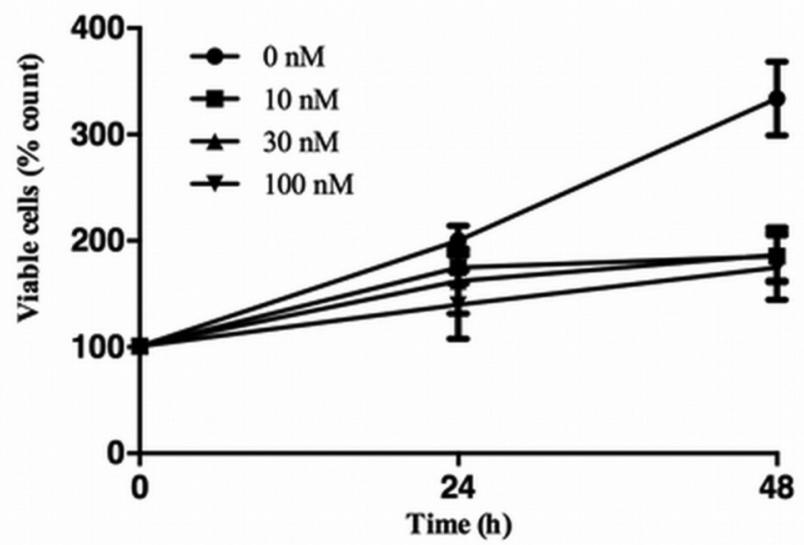

Figure 1. Gemcitabine inhibits the proliferation of PDAC cells. PDAC cells were incubated with 0, 10, 30, or 100 nmol/l gemcitabine for 48 h. Cell proliferation was evaluated by the CCK-8 assay. The results are expressed as the percentage of viable cells compared with the control ( $0 \mathrm{nmol} / \mathrm{l})$. All treatments were significantly different from the control, based on Student's t-test $(* p<0.05$ and $* * p<0.01$ vs. control).

treated with various concentrations of gemcitabine $(0,10,30$, or $100 \mathrm{nM}$ ) for $48 \mathrm{~h}$. Treatment of PK-1 and PK-9 cells with gemcitabine for $48 \mathrm{~h}$ reduced their proliferation in a dosedependent manner (Figure 1).

Gemcitabine induces $S$ phase cell cycle arrest and regulates cell cycle-related proteins in PK-1 cells. We further investigated the effects of gemcitabine on the cell cycle of PK-1 cells by flow cytometric analysis. After treatment with $30 \mathrm{nM}$ gemcitabine for 24 or $48 \mathrm{~h}$, the percentage of PK-1 cells in the $G_{0} / G_{1}$ phase was increased compared with control cells $(56.48 \%$ vs. $34.14 \%$ after $24 \mathrm{~h}, 61.23 \%$ vs. $38.76 \%$ after $48 \mathrm{~h}$ ) (Figure $2 \mathrm{~A}$ ). As the proportion of cells in the $\mathrm{G} 0 / \mathrm{G} 1$ phase increased, the proportion of cells in the $\mathrm{S}$ phase was decreased $(29.57 \%$ vs. $36.67 \%$ after 24 h, $38.76 \%$ vs. $41.20 \%$ after $48 \mathrm{~h}$ ). This accumulation was associated with a reduction of $\mathrm{G} 2 / \mathrm{M}$ phase cells. We further found that the expression levels of cyclin D1 as well as CDK4 and
CDK6, the catalytic partners of cyclin D1, were decreased in PK-1 cells after gemcitabine treatment (Figure 2B and C). Together these results indicated that the growth of PDAC cells was suppressed after gemcitabine treatment by impairing cell cycle progression.

Gemcitabine treatment suppresses growth of tumours derived from human PDAC cells. We next investigated the antitumour effect of gemcitabine in vivo. Xenografted mice were intraperitoneally administrated gemcitabine ( 40 or $80 \mathrm{mg} / \mathrm{kg}$ ) or PBS after subcutaneous implantation of PK-1 cells. Gemcitabine effectively suppressed the tumour growth from PK-1 xenografts (Figure 3A). The tumour size was significantly smaller in gemcitabine-treated mice compared with the controls (Figure 3B). We also analysed tumour sections by immunohistochemistry to determine whether gemcitabine also affected cyclin D1 in vivo. Gemcitabine treatment resulted in decreased expression levels of cyclin 

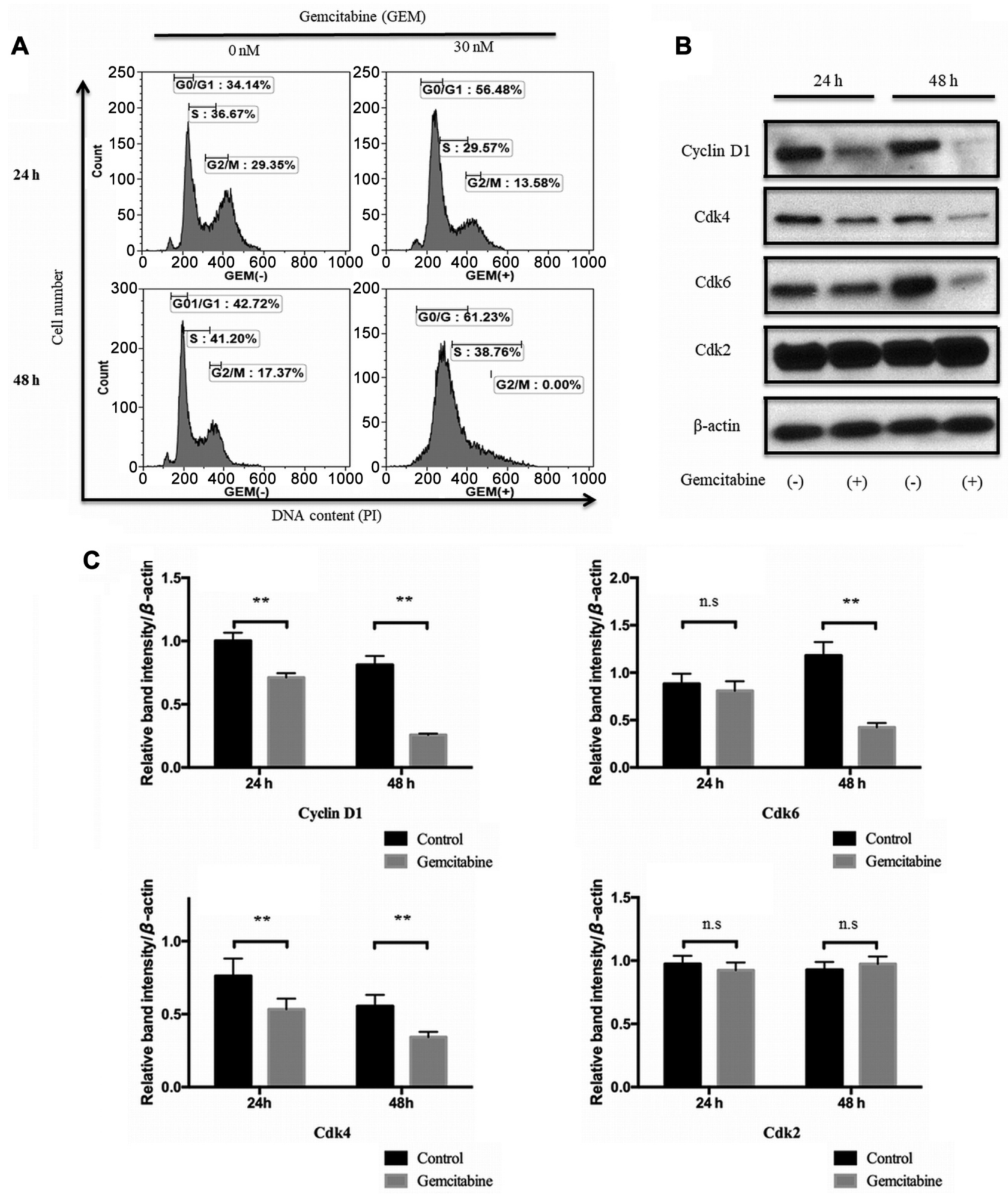

Figure 2. Gemcitabine induces $S$ phase arrest in $P K-1$ cells (A) Representative results showing the distribution of PK-1 cells in G0/G1, S, and G2/M phases following treatment with $30 \mathrm{nM}$ gemcitabine for 24 and $48 \mathrm{~h}$. (B) Western blot showing expression of cyclin D1, CDK4, and CDK6 in PK1 cells following treatment with $30 \mathrm{nM}$ gemcitabine for 24 and $48 \mathrm{~h}$. (C) Cyclin D1, CDK4, and CDK6 expression were decreased by $30 \mathrm{nM}$ gemcitabine treatment compared with the control. The images are representative of three independent experiments, and protein levels were normalized to $\beta$-actin. Values represent mean $\pm S D ; * p<0.05$ and $* * p<0.01$ vs. control. n.s: Not significant. 
A

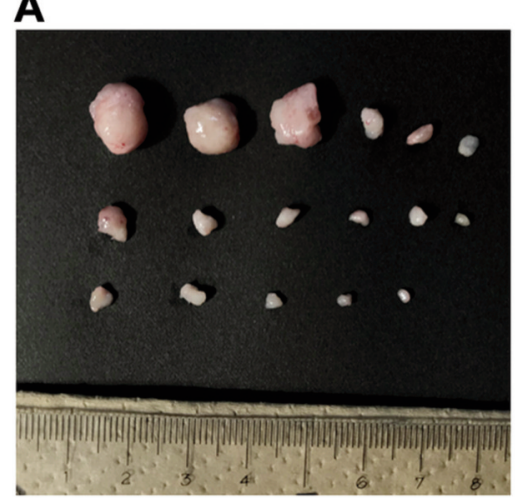

B

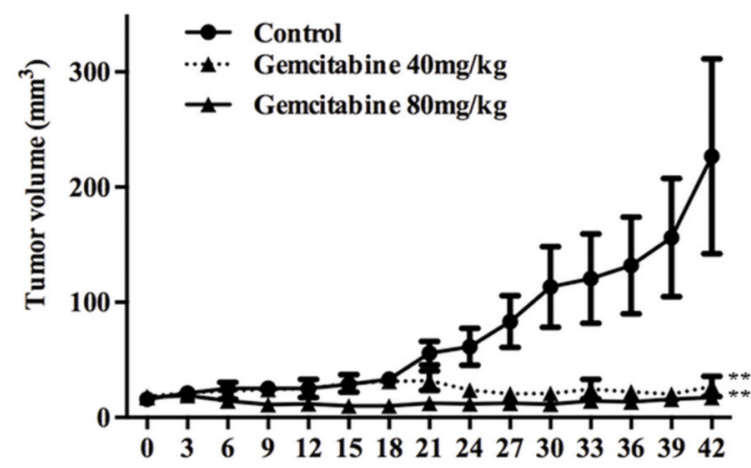

C

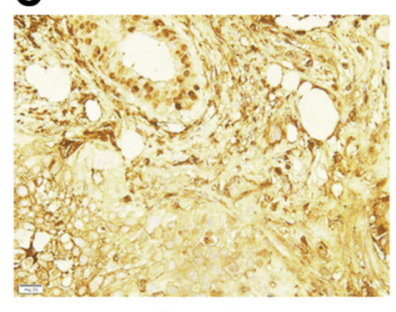

Control

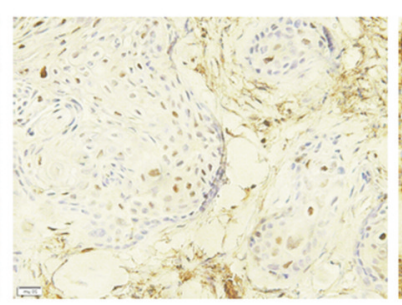

GEM 40mg/day

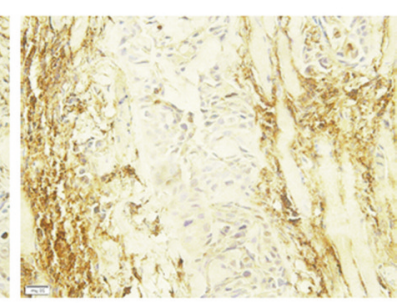

GEM $80 \mathrm{mg} / \mathrm{day}$

D

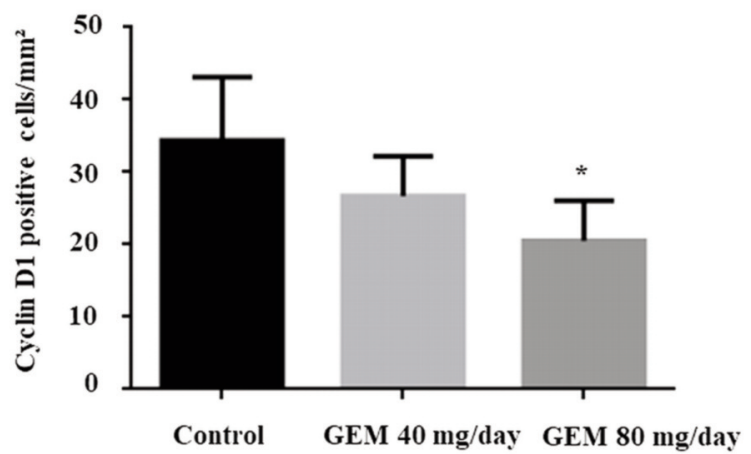

Days after gemcitabine injection

Figure 3. Gemcitabine inhibits the growth of PK-1 cell xenografts in nude mice. PK-1 cells were subcutaneously implanted into the flanks of nude mice. When the tumours became palpable, 0,40 or $80 \mathrm{mg} / \mathrm{kg}$ gemcitabine were intraperitoneally injected five times per week for 42 days. (A) Tumour growth curves of control and gemcitabine treatment groups. (B) Tumours were significantly smaller in gemcitabine-treated mice compared with vehicle-treated mice. Each point represents the mean \pm standard deviation of eight animals $(* p<0.05$ and $* * p<0.01$ vs. control). (C) Immunohistochemical staining of cyclin D1 in cancerous tissues from gemcitabine-treated and control groups of xenografted mice. Cyclin D1positive cells (black arrows) were decreased in mice treated with gemcitabine.(D) Cyclin D1-positive cells in gemcitabine-treated mice were reduced compared with untreated mice.

D1 compared to controls (Figure 3C). The labelling index of gemcitabine-treated cell was also lower compared to controls (Figure 3D). Gemcitabine treatment had no significant effect on the body weight of animals during the treatments.

Gemcitabine treatment alters the miRNA profile in gemcitabine-treated PK-1 cells and tumour tissues. Heat maps generated by miRNA microarray analysis revealed dysregulated expression of several miRNAs in gemcitabinetreated PK-1 cells and tumour tissues (Figure 4A). We examined the expression levels of 2555 miRNAs in PK-1 cells with or without $30 \mathrm{nM}$ gemcitabine treatment. After normalization and removing miRNAs with missing values, 241 miRNAs were used to perform hierarchical clustering. Finally, 14 significantly altered miRNAs were identified. Of these, 11 were significantly up-regulated miRNAs and 3 were significantly down-regulated miRNAs. The miRNAs that were up-regulated included miR-338-3p, miR-132-3p,
miR-135b-5p, miR-455-3p, miR-345-5p, miR-4506, miR3653-3p, miR-191-5p, miR-424-5p, miR-34a-3p, and miR$34 a-5 p$ (Table I). Those that showed significantly increased expression levels were miR-5100, miR-19b-1-5p, and miR205-3p (Table I).

In addition, 29 significantly altered miRNAs were identified in xenograft tumour tissues with or without gemcitabine treatment (Figure 4B), including 7 significantly up-regulated and 22 significantly down-regulated miRNAs (Table II).

\section{Discussion}

In the present study, we examined the effects of gemcitabine in PDAC. Gemcitabine induced cell cycle arrest at the $\mathrm{S}$ phase through the modulation of the cell cycle-regulating protein cyclin D1 in PK-1 cells. We also identified the miRNA signature of gemcitabine in PDAC cells and a 
A

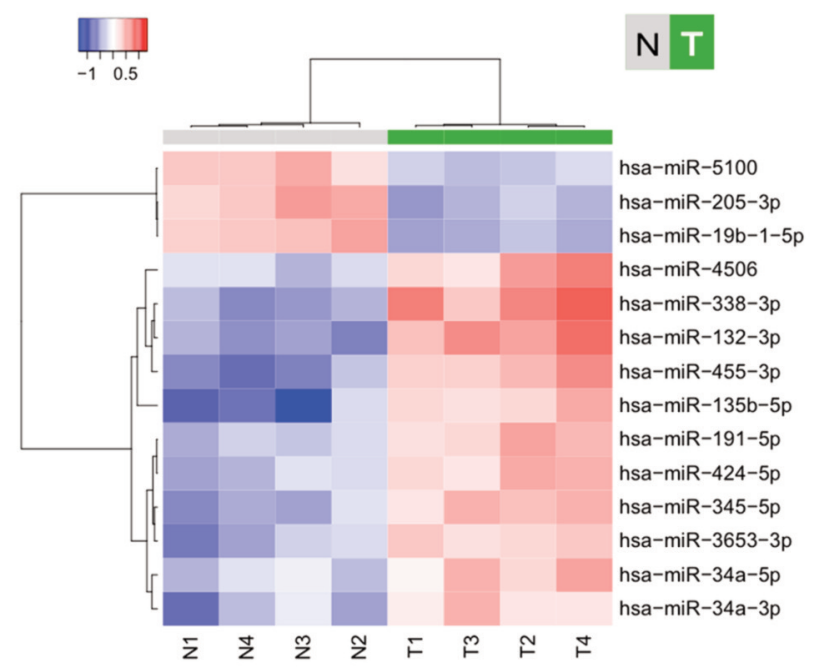

B

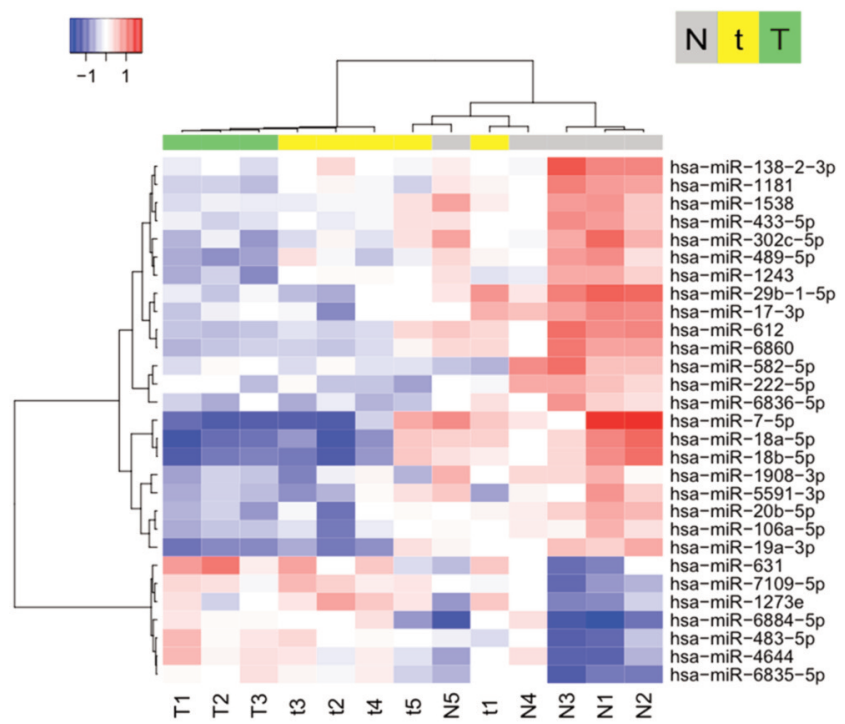

Figure 4. Hierarchical clustering of miRNAs in (A) PK-1 cells and (B) tumour tissues treated with or without gemcitabine. The analysed samples are shown in the columns, and the miRNAs are presented in the rows. The miRNA clustering colour scale presented at the top indicates the relative miRNA expression levels; red and blue represent high and low expression levels, respectively. Gray scale indicates no treatment. Yellow scale indicates $40 \mathrm{mg} / \mathrm{kg}$ gemcitabine, and light green scale indicates $80 \mathrm{mg} / \mathrm{kg}$ gemcitabine.

xenograft model. To the best of our knowledge, this is the first study to show that the miRNA signature of the antitumour effect of gemcitabine associated with cell proliferation and tumour growth in vitro and in vivo.

Gemcitabine is a deoxycytidine analogue and its cytotoxic activity is based on several activities in DNA synthesis (16). As a cytidine analogue, gemcitabine is incorporated into DNA during replication in the $S$ phase of cell cycle. Gemcitabine is used as chemotherapy for pancreas, breast, ovarian, and non-small-cell lung cancer (16), and it is the standard of care for patients with these tumours (17). Gemcitabine exerts its activity primarily by inducing cell cycle arrest and cell death $(18,19)$. Our results showed that gemcitabine induced a time- and concentration-dependent cell cycle arrest at the $S$ phase, which is consistent with previous results $(20,21)$. The gemcitabine-induced $S$ phase arrest was detected as both an increase in the transition rate from $G_{0} / G_{1}$ and an inhibition of the transition rate from $S$ phase to $G_{2} / M$ phase. The $\mathrm{S}$ phase arrest was increased with gemcitabine concentration (22). In the present study, gemcitabine treatment in PK-1 and PK-9 cells led to a strong, dosedependent inhibition of cell proliferation. However, gemcitabine did not exert an anti-proliferative effect on PANC-1 cells, which are considered relatively resistant to many chemotherapeutic regimens (23). Additionally, the expression levels of cyclin D1 was decreased in PK-1 cells after gemcitabine treatment. Cyclin D1 is an important interacting partner for CDK4 and CDK6 and regulates the
Table I. Statistical results and chromosomal locations of miRNAs in PK-1 cells treated with or without gemcitabine. Fold changes are gemcitabinetreated/non-treated. Fold change $(F C)>1.5, F C<0.4, p<0.005$.

\begin{tabular}{lccc}
\hline miRNA & $\begin{array}{c}\text { Fold change } \\
(\mathrm{T} / \mathrm{N})\end{array}$ & $\begin{array}{c}\text { Chromosomal } \\
\text { localization }\end{array}$ & $p$-Value \\
\hline $\begin{array}{l}\text { Up-regulated } \\
\text { hsa-miR-338-3p }\end{array}$ & 2.237 & $17 \mathrm{q} 25.3$ & 0.000099 \\
hsa-miR-132-3p & 2.206 & $17 \mathrm{p} 13.3$ & 0.000046 \\
hsa-miR-135b-5p & 2.099 & $1 \mathrm{q} 32.1$ & 0.002882 \\
hsa-miR-455-3p & 2.016 & $9 \mathrm{q} 32$ & 0.000275 \\
hsa-miR-345-5p & 1.711 & $14 \mathrm{q} 32.2$ & 0.000433 \\
hsa-miR-4506 & 1.639 & $14 \mathrm{q} 32.12$ & 0.003404 \\
hsa-miR-3653-3p & 1.617 & $22 \mathrm{q} 12.2$ & 0.000703 \\
hsa-miR-191-5p & 1.614 & $3 \mathrm{p} 21.31$ & 0.00018 \\
hsa-miR-424-5p & 1.593 & $\mathrm{Xq} 26.3$ & 0.000601 \\
hsa-miR-34a-3p & 1.58 & $1 \mathrm{p} 36.22$ & 0.00453 \\
hsa-miR-34a-5p & 1.525 & $1 \mathrm{p} 36.22$ & 0.002963 \\
Down-regulated & & & \\
hsa-miR-5100 & 0.631 & $10 \mathrm{q} 11.21$ & 0.000035 \\
hsa-miR-19b-1-5p & 0.571 & $13 \mathrm{q} 31.3$ & 0.000025 \\
hsa-miR-205-3p & 0.559 & $1 \mathrm{q} 32.2$ & 0.000064 \\
\hline
\end{tabular}

cell cycle transition from $\mathrm{G}_{1}$ to $\mathrm{S}$ phase (24). Increased cyclin D1 expression is associated poor prognosis (25) and decreased postoperative survival (26) of PDAC patients. Therefore, suppression of cyclin D1 with gemcitabine treatment was associated with the growth-inhibitory effect of 
Table II. Statistical results and chromosomal locations of miRNAs in $P K-1$ cell-derived tumour tissues treated with or without gemcitabine. Fold changes are gemcitabine-treated/non-treated $(T / N)$. Fold change $(F C)>1.5, F C<0.67, p<0.01$.

\begin{tabular}{|c|c|c|c|}
\hline miRNA & $\begin{array}{l}\text { Fold change } \\
\qquad(\mathrm{T} / \mathrm{N})\end{array}$ & $\begin{array}{c}\text { Chromosomal } \\
\text { localization }\end{array}$ & $p$-Value \\
\hline \multicolumn{4}{|l|}{ Up-regulated } \\
\hline hsa-miR-631 & 1.88 & $15 q 24.2$ & 0.0061 \\
\hline hsa-miR-6884-5p & 1.77 & $17 q 21.1$ & 0.007 \\
\hline hsa-miR-1273e & 1.75 & $17 q 23.3$ & 0.0014 \\
\hline hsa-miR-6835-5p & 1.61 & $6 \mathrm{p} 21.31$ & 0.0025 \\
\hline hsa-miR-4644 & 1.6 & $6 q 27$ & 0.0087 \\
\hline hsa-miR-7109-5p & 1.6 & $22 q 12.2$ & 0.0029 \\
\hline hsa-miR-483-5p & 1.57 & $11 \mathrm{p} 15.5$ & 0.0089 \\
\hline \multicolumn{4}{|l|}{ Down-regulated } \\
\hline hsa-miR-7-5p & 0.35 & $9 q 21.32$ & 0.0059 \\
\hline hsa-miR-18a-5p & 0.45 & $13 q 31.3$ & 0.0058 \\
\hline hsa-miR-18b-5p & 0.46 & $\mathrm{Xq} 26.2$ & 0.0043 \\
\hline hsa-miR-612 & 0.53 & $11 \mathrm{q} 13.1$ & 0.0019 \\
\hline hsa-miR-29b-1-5p & 0.54 & $7 \mathrm{q} 32.3$ & 0.0062 \\
\hline hsa-miR-19a-3p & 0.55 & $13 \mathrm{q} 31.3$ & 0.0026 \\
\hline hsa-miR-302c-5p & 0.55 & $4 q 25$ & 0.0028 \\
\hline hsa-miR-6860 & 0.55 & $11 \mathrm{q} 13.2$ & 0.0017 \\
\hline hsa-miR-582-5p & 0.57 & $5 \mathrm{q} 12.1$ & 0.009 \\
\hline hsa-miR-138-2-3p & 0.58 & $16 \mathrm{q} 13$ & 0.0095 \\
\hline hsa-miR-1181 & 0.59 & $19 \mathrm{p} 13.2$ & 0.0022 \\
\hline hsa-miR-1908-3p & 0.59 & $11 \mathrm{q} 12.2$ & 0.0011 \\
\hline hsa-miR-17-3p & 0.6 & $13 \mathrm{q} 31.3$ & 0.0068 \\
\hline hsa-miR-489-5p & 0.6 & $7 q 21.3$ & 0.0065 \\
\hline hsa-miR-5591-3p & 0.6 & $4 \mathrm{p} 14$ & 0.0036 \\
\hline hsa-miR-222-5p & 0.62 & Xp11.3 & 0.0011 \\
\hline hsa-miR-1538 & 0.63 & $16 \mathrm{q} 22.1$ & 0.0018 \\
\hline hsa-miR-20b-5p & 0.63 & $\mathrm{Xq} 26.2$ & 0.0067 \\
\hline hsa-miR-106a-5p & 0.66 & $\mathrm{Xq} 26.2$ & 0.0036 \\
\hline hsa-miR-1243 & 0.66 & $4 q 25$ & 0.0099 \\
\hline hsa-miR-433-5p & 0.66 & $14 \mathrm{q} 32.2$ & 0.0038 \\
\hline hsa-miR-6836-5p & 0.66 & $7 \mathrm{p} 22.3$ & 0.0073 \\
\hline
\end{tabular}

other chemotherapeutic agents and decreased expression of multiple chemoresistance genes in human PDAC cells (27).

In addition to its effects upon the cell cycle, gemcitabine induces caspase-3-mediated apoptosis (28). Hamed et al have revealed that the apoptotic effect of gemcitabine was more evident at later time points of treatment (72 and $96 \mathrm{~h}$ ) (29). These results suggest that gemcitabine induces cell cycle arrest in the early phase (24-48 h after gemcitabine treatment) and that the apoptotic effects of gemcitabine take place at later time points (72 and $96 \mathrm{~h}$ ).

Cell cycle regulation is crucial for cell growth and many miRNAs are involved in the negative control of cell cycle genes, which are essential during oncogenesis of PDAC (30). miRNAs are endogenous mediators of gene expression through their site-specific binding at the 3' untranslated region or other sites of mRNAs to either degrade their target or inactivate protein synthesis (31). miRNAs regulate many biological processes such as cancer cell proliferation, tumour growth, differentiation, apoptosis, and energy metabolism (32). We identified miRNAs associated with the anti-tumour effects of gemcitabine in PK-1 cells using miRNA expression arrays. Several miRNAs were significantly altered following gemcitabine treatment of PK-1 cells. Among these, miR-338$3 \mathrm{p}$ has been shown to be up-regulated in pancreatic intraepithelial neoplasms, which is a precursor lesion of PDAC (33). However, the role of miR-338-3p in advanced PDAC remains unknown. Overexpression of miR-338-3p Has been shown to promote cell proliferation, migration, and invasion in gastric cancer by targeting metastasis-associated in colon cancer-1 (MACC1) (34). Our results showed that miR-338-3p expression levels were significantly increased in gemcitabinetreated PK-1 cells. Overexpression of miR-582-5p Has been shown to induce colorectal cancer cell proliferation by increasing cyclin D1 expression (35). Gemcitabine to significantly down-regulate miR-582-5p in PK-1 xenograft tissues, and down-regulation of miR-582-5p may contribute to suppressed cancer proliferation via modulating cell cycle-related proteins (35). Although several miRNAs were significantly altered in PK-1 xenograft tumour tissues from mice following $40 \mathrm{mg}$ and $80 \mathrm{mg}$ gemcitabine treatment, we did not identify any overlapping significantly altered miRNAs from cultured cells and tumour tissues following gemcitabine treatment.

In conclusion, our results revealed that gemcitabine inhibits human PDAC cell proliferation by inducing cell cycle arrest. Additionally, we identified numerous miRNAs associated with the anti-tumour effects of gemcitabine in PDAC cells and tumour tissues using miRNA expression arrays. This aberrant miRNA expression signature may provide insights into PDAC development and therapeutic opportunities to improve gemcitabine monotherapy.

\section{Conflicts of Interest}

The Authors disclose no potential conflicts of interest related to this study.

\section{Authors' Contributions}

DN and TM designed experiments. SF, HI, KF, TM, MN, MO, MH, TK, NF, HY, KK, HKa, AM, HKo, and KT conducted the experiments, data analysis, and final drafting and writing of the manuscript. SF contributed to drafting of the manuscript. TM was involved in the research design and drafting of the final manuscript. All Authors have read and approved the final version of the manuscript.

\section{Acknowledgements}

The Authors thank Ms. Kayo Hirose, Ms. Keiko Fujikawa, and Ms. Fuyuko Kokado for their skilful technical assistance. The Authors also thank Edanz Group (https://en-author-services.edanzgroup.com/) for editing a draft of this manuscript. 


\section{References}

1 GBD 2017 Pancreatic Cancer Collaborators: The global, regional, and national burden of pancreatic cancer and its attributable risk factors in 195 countries and territories, 19902017: a systematic analysis for the Global Burden of Disease Study 2017. Lancet Gastroenterol Hepatol 4(12): 934-947, 2019. PMID: 31648972. DOI: 10.1016/S2468-1253(19)30347-4

2 Howes N, Lerch MM, Greenhalf W, Stocken DD, Ellis I, Simon P, Truninger K, Ammann R, Cavallini G, Charnley RM, Uomo G, Delhaye M, Spicak J, Drumm B, Jansen J, Mountford R, Whitcomb DC and Neoptolemos JP: Clinical and genetic characteristics of hereditary pancreatitis in Europe. Clin Gastroenterol Hepatol 2(3): 252, 2004. PMID: 15017610. DOI: $10.1016 / \mathrm{s} 1542-3565(04) 00013-8$

3 Kamisawa T, Wood LD, Itoi T and Takaori K: Pancreatic cancer. Lancet 388(10039): 73-85, 2016. PMID: 26830752. DOI: 10.1016/S0140-6736(16)00141-0

4 Neoptolemos JP, Stocken DD, Friess H, Bassi C, Dunn JA, Hickey H, Beger H, Fernandez-Cruz L, Dervenis C, Lacaine F, Falconi M, Pederzoli P, Pap A, Spooner D, Kerr DJ, Büchler MW and European Study Group for Pancreatic Cancer: A randomized trial of chemoradiotherapy and chemotherapy after resection of pancreatic cancer. N Engl J Med 350: 1200-1210, 2004. PMID: 15028824. DOI: 10.1056/NEJMoa032295

5 Vaccaro V, Sperduti I, Vari S, Bria E, Melisi D, Garufi C, Nuzzo C, Scarpa A, Tortora G, Cognetti F, Reni M and Milella M: Metastatic pancreatic cancer: Is there a light at the end of the tunnel? World J Gastroenterol 21(16): 4788-4801, 2015. PMID: 25944992. DOI: $10.3748 /$ wjg.v21.i16.4788

6 Burris HA III, Moore MJ, Andersen J, Green MR, Rothenberg ML, Modiano MR, Cripps MC, Portenoy RK, Storniolo AM, Tarassoff P, Nelson R, Dorr FA, Stephens CD and Von Hoff DD: Improvements in survival and clinical benefit with gemcitabine as first-line therapy for patients with advanced pancreas cancer: a randomized trial. J Clin Oncol 15: 2403-2413, 1997. PMID: 9196156. DOI: 10.1200/JCO.1997.15.6.2403

7 Oettle H, Post S, Neuhaus P, Gellert K, Langrehr J, Ridwelski K, Schramm H, Fahlke J, Zuelke C, Burkart C, Gutberlet K, Kettner E, Schmalenberg H, Weigang-Koehler K, Bechstein WO, Niedergethmann M, Schmidt-Wolf I, Roll L, Doerken B and Riess $\mathrm{H}$ : Adjuvant chemotherapy with gemcitabine vs observation in patients undergoing curative-intent resection of pancreatic cancer: a randomized controlled trial. JAMA 297: 267-277, 2007. PMID: 17227978. DOI: 10.1001/jama.297.3.267

8 Pasquinelli AE: MicroRNAs and their targets: recognition, regulation and an emerging reciprocal relationship. Nat Rev Genet 13: 271-282, 2012. PMID: 22411466. DOI: $10.1038 / \mathrm{nrg} 3162$

9 Kozinn SI, Harty NJ, Delong JM, Deliyiannis C, Logvinenko T, Summerhayes IC, Libertino JA, Holway AH and Rieger-Christ KM: MicroRNA profile to predict gemcitabine resistance in bladder carcinoma cell lines. Genes Cancer 4: 61-69, 2013. PMID: 23946872. DOI: 10.1177/1947601913484495

$10 \mathrm{Li} \mathrm{H}$ and Yang BB: Friend or foe: the role of microRNA in chemotherapy resistance. Acta Pharmacol Sin 34: 870-879, 2013. PMID: 23624759. DOI: 10.1038/aps.2013.35

11 Kawaguchi T, Komatsu S, Ichikawa D, Morimura R, Tsujiura M, Konishi H, Takeshita H, Nagata H, Arita T, Hirajima S, Shiozaki A, Ikoma H, Okamoto K, Ochiai T, Taniguchi $\mathrm{H}$ and Otsuji E: Clinical impact of circulating miR-221 in plasma of patients with pancreatic cancer. Br J Cancer 108: 361-369, 2013. PMID: 23329235. DOI: $10.1038 / \mathrm{bjc} .2012 .546$

12 Zhao G, Zhang JG, Liu Y, Qin Q, Wang B, Tian K, Liu L, Li X, Niu Y, Deng SC and Wang CY: miR-148b functions as a tumor suppressor in pancreatic cancer by targeting AMPK $\alpha 1$. Mol Cancer Ther 12: 83-93, 2013. PMID: 23171948. DOI: 10.1158/ 1535-7163.MCT-12-0534-T

13 Chen WY, Liu WJ, Zhao YP, Zhou L, Zhang TP, Chen G and Shu H: Induction, modulation and potential targets of miR-210 in pancreatic cancer cells. Hepatobiliary Pancreat Dis Int 11: 319-324, 2012. PMID: 22672828. DOI: 10.1016/s14993872(12)60168-4

14 Toyota Y, Iwama H, Kato K, Tani J, Katsura A, Miyata M, Fujiwara S, Fujita K, Sakamoto T, Fujimori T, Okura R, Kobayashi K, Tadokoro T, Mimura S, Nomura T, Miyoshi H, Morishita A, Kamada H, Yoneyama H, Okano K, Suzuki Y and Masaki T: Mechanism of gemcitabine-induced suppression of human cholangiocellular carcinoma cell growth. Int J Oncol 47(4): 1293-1302, 2015. PMID: 26252371. DOI: 10.3892/ijo.2015.3118

15 Miyata M, Morishita A, Sakamoto T, Katsura A, Kato K, Nishioka T, Toyota Y, Fujita K, Maeda E, Nomura T, Tani J, Miyoshi H, Yoneyama H, Kobara H, Fujiwara S, Nishiyama N, Iwama H, Himoto T, Hirashima M and Masaki T: MicroRNA profiles in cisplatin-induced apoptosis of hepatocellular carcinoma cells. Int J Oncol 47(2): 535-542, 2015. PMID: 26060089. DOI: 10.3892/ijo.2015.3036

16 Calabretta S, Bielli P, Passacantilli I, Pilozzi E, Fendrich V, Capurso G, Fave GD and Sette C: Modulation of PKM alternative splicing by PTBP1 promotes gemcitabine resistance in pancreatic cancer cells. Oncogene 35: 2031-2039, 2016. PMID: 26234680. DOI: 10.1038/onc.2015.270

17 Binenbaum Y, Na' ara S and Gil Z: Gemcitabine resistance in pancreatic ductal adenocarcinoma. Drug Resist Updat 23: 55-68, 2015. PMID: 26690340. DOI: 10.1016/j.drup.2015.10.002

18 Hui YF and Reitz J: Gemcitabine: a cytidine analogue active against solid tumors. Am J Health Syst Pharm 54: 162-170, 1997. PMID: 9117804. DOI: 10.1093/ajhp/54.2.162

19 Carpenelli G, Bucci G, D’Agnano I, Canese R, Caroli F, Raus L, Brunetti E, Giannarelli E, Podo F and Carapella CM: Gemcitabine treatment of experimental C6 glioma: the effects on cell cycle and apoptotic rate. Anticancer Res 26: 3017-3024, 2006. PMID: 16886629

20 Zhang C, Li H, Wang J, Zhang J and Hou X: MicroRNA-338$3 p$ suppresses cell proliferation, migration and invasion in human malignant melanoma by targeting MACC1. Exp Ther Med 18(2): 997-1004, 2019. PMID: 31316597. DOI: 10.3892/etm.2019.7644

21 Y Galmarini CM, Clarke ML, Falette N, Puisieux A, Mackey JR and Dumontet C: Expression of a non-functional p53 affects the sensitivity of cancer cells to gemcitabine. Int J Cancer 97(4): 439-445, 2002. PMID: 11802204. DOI: 10.1002/ijc.1628

22 Morgan MA, Parsels LA, Parsels JD, Mesiwala AK, Maybaum $\mathrm{J}$ and Lawrence TS: Role of checkpoint kinase 1 in preventing premature mitosis in response to gemcitabine. Cancer Res 65: 6835-6842, 2005. PMID: 16061666. DOI: 10.1158/0008-5472. CAN-04-2246

23 Cappella P, Tomasoni D, Faretta M, Lupi M, Montalenti F, Viale F, Banzato F, D'Incalci M and Ubezio P: Cell cycle effects of gemcitabine. Int J Cancer 93: 401-408, 2001. PMID: 11433406. DOI: $10.1002 /$ ijc.1351 
24 Rejiba S, Wack S, Aprahamian M and Hajri A: K-ras oncogene silencing strategy reduces tumor growth and enhances gemcitabine chemotherapy efficacy for pancreatic cancer treatment. Cancer Sci 98: 1128-1136, 2007. PMID: 17489984. DOI: $10.1111 / \mathrm{j} .1349-7006.2007 .00506 . x$

25 Sherr CJ: $\mathrm{G}_{1}$ phase progression: cycling on cue. Cell 79: 551-555, 1994. PMID: 7954821. DOI: 10.1016/0092-8674(94)90540-1

26 Gansauge S, Gansauge F, Ramadani M, Stobbe H, Rau B, Harada N and Beger HG: Overexpression of cyclin D1 in human pancreatic carcinoma is associated with poor prognosis. Cancer Res 57: 1634-1637, 1997. PMID: 9134998.

27 Zhu HQ, Ma JB, Song X, Gao HJ, Ma CQ, Chang H, Li HG, Liu FF, Lu J and Zhou X: Metformin potentiates the anticancer activities of gemcitabine and cisplatin against cholangiocarcinoma cells in vitro and in vivo. Oncol Rep 36: 3488-3496, 2016. PMID: 27779693. DOI: 10.3892/or.2016.5187

28 Kornmann M, Ishiwata T, Itakura J, Tangvoranuntakul P, Beger HG and Korc M: Increased cyclin D1 in human pancreatic cancer is associated with decreased postoperative survival. Oncology 55: 363-369, 1998. PMID: 9663429. DOI: 10.1159/ 000011879

29 Chandler NM, Canete JJ and Callery MP: Caspase-3 drives apoptosis in pancreatic cancer cells after treatment with gemcitabine. J Gastrointest Surg 8: 1072-1078, 2004. PMID: 15585396. DOI: 10.1016/j.gassur.2004.09.054

30 Hamed SS, Straubinger RM and Jusko WJ: Pharmaco-dynamic modeling of cell cycle and apoptotic effects of gemcitabine on pancreatic adenocarcinoma cells. Cancer Chemother Pharmacol 72(3): 553-563, 2013. PMID: 23835677. DOI: 10.1007/s00280013-2226-6
31 Drakaki A and Iliopoulos D: MicroRNA-gene signaling pathways in pancreatic cancer. Biomed J 36: 200-208, 2013. PMID: 24225187. DOI: 10.4103/2319-4170.119690

32 Meng F, Henson R, Lang M, Wehbe H, Maheshwari S, Mendell JT, Jiang J, Schmittgen TD and Patel T: Involvement of human micro-RNA in growth and response to chemotherapy in human cholangiocarcinoma cell lines. Gastroenterology 130: 2113 2129, 2006. PMID: 16762633. DOI: 10.1053/j.gastro. 2006.02.057

33 Morishita A and Masaki T: miRNA in hepatocellular carcinoma. Hepatology Res 45: 128-141, 2015. PMID: 25040738. DOI: 10.1111/hepr.12386

$34 \mathrm{Yu}$ J, Li A, Hong SM, Hruban RH and Goggins M: MicroRNA alterations of pancreatic intraepithelial neoplasias. Clin Cancer Res 18(4): 981-992, 2012. PMID: 22114139. DOI: 10.1158/ 1078-0432.CCR-11-2347

35 Shu Z, Chen L and Ding D: miR-582-5P induces colorectal cancer cell proliferation by targeting adenomatous polyposis coli. World J Surg Oncol 14(1): 239, 2016. PMID: 27595705. DOI: 10.1186/s12957-016-0984-4
Received May 28, 2020

Revised July 24, 2020

Accepted July 27, 2020 